\title{
O APPROACH DA COMPLEXIDADE AO DIREITO E ECONOMIA: UMA NECESSÁRIA INTERAÇÃO
}

\section{THE COMPLEXITY APPROACH TO LAW AND ECONOMICS: A NECESSARY INTERACTION}

\author{
${ }^{1}$ Antonio Bazilio Floriani Neto \\ ${ }^{2}$ Lara Bonemer Azevedo da Rocha
}

\section{RESUMO}

O presente artigo tem como objetivo propor uma aproximação entre direito, economia e complexidade. Busca demonstrar a insuficiência de uma visão reducionista e estática dos fenômenos sociais para solucionar problemas e, com isso, apresenta o método complexo como instrumental analítico necessário. Apresenta uma breve evolução do pensamento econômico, sob o viés da nova economia institucional (NEI). Em seguida, analisa a Economia da Complexidade para, ao final, propor a interação como mecanismo de aprimoramento do ferramental econômico.

Palavras-chave: Direito e Economia; Complexidade; Nova Economia Institucional; Desenvolvimento; Economia da Complexidade.

\begin{abstract}
This article aims to propose an approximation of law, economics and complexity. It seeks to demonstrate the inadequacy of a reductionist and static view of the social phenomena to solve problems and, therefore, presents the complex method as necessary analytical tool. It presents a brief evolution of economic thought, under the bias of the New Institutional Economics (NIE). Then analyzes the Complexity Economics to propose, at the end, the interaction as an improvement mechanism of economics.
\end{abstract}

Keywords: Law and Economics; Complexity; New Institutional Economics; Development; Complexity Economics.

\footnotetext{
${ }^{1}$ Doutorando e mestre em Direito Econômico pela Pontifícia Universidade Católica do Paraná (PUCPR), Curitiba, Paraná, Brasil. Editor da Revista de Direito Empresarial. Advogado. Email: antonio@ rochaefloriani.com.br

${ }^{2}$ Doutoranda em direito econômico pela Universidade Católica do Paraná (PUCPR), Curitiba, Paraná, Brasil. Bolsista pela Coordenação de Aperfeiçoamento de Pessoal de Nível Superior (CAPES). Mestre em direito econômico e socioambiental. Editora-Geral da Revista de Direito Empresarial. Email: lara@ rochaefloriani.com.br
} 


\section{INTRODUÇÃO}

A teoria dos sistemas complexos promoveu um grande avanço na ciência econômica na década de 1980, expandindo a compreensão de economistas sobre suas teorias e fundamentos. Percebeu-se, conforme explica Beinhocker em sua obra, "The Origin of Wealth"3, que a teoria econômica encontrava-se em um momento de alta idealização teórica, insuscetível ao uso de dados e com suas atenções voltadas para modelos inaplicáveis ao mundo real.

Esse pacote de ideias, compreendido pelas escolas de pensamento de teoria econômica ${ }^{4}$, dominou o século passado e caracteriza-se pela visão convencional, cujas ideias estão presentes nos livros universitários, na mídia e que têm a finalidade de introduzir o sujeito à essa ciência ${ }^{5}$. Como exemplo, estão os conceitos de racionalidade ilimitada ${ }^{6}$ (ideia que os indivíduos estão, a toda hora, calculando e tomando decisões que irão maximizar seu bem-estar), a desconsideração do tempo e das instituições na tomada de decisões ${ }^{7}$ e a persistência de "leis" antigas, como por exemplo a da oferta e procura ${ }^{8}$.

Contudo, em face da crise econômica que assolou o mundo na década de 1980, um grupo liderado por George Cowan e Murray Gell-Mann, reuniu-se na Universidade de Santa Fé, no estado norte-americano do Novo México, com a ambição de modificar o modo de condução da pesquisa científica. Observou-se a predominância do imperativo reducionista, o qual propaga homogeneidade sintática por meio de um pensamento simplificador, "[...] que mutila a realidade em partes estanques, a serem estudadas, cada uma, em isolamento, perante as demais"9.

Vale dizer, a ciência, em especial a econômica, acreditava que quebra do universo em partes menores e o aprofundamento dessa partícula seria suficiente para compreensão de uma realidade complexa e transitória. Esse modo de agir, consistente na dissecação do objeto,

3 BEINHOCKER, Eric D. The origin of wealth: evolution, complexity and the radical remaking of economics. Harvard Business School Press: Boston, Massachusetts, 2006.

4 Dentre as quais destacam-se: Economia política (Adam Smith, David Ricardo, Thomas Malthus, John Stuart Mill); Economia neoclássica - institucionalistas (Thorstein Veblen, Jeremy Bentham, Vilfredo Pareto, Carl Menger, Alfred Marshall); Economia marxista (Karl Marx), entre outras. O presente estudo será voltado à teoria institucional e nova economia institucional, que será objeto do próximo item.

5 BEINHOCKER, Eric D. The origin of wealth: evolution, complexity and the radical remaking of economics. Harvard Business School Press: Boston, Massachusetts, 2006, p. 23-24.

$6 \quad$ Ibid. p. 51-52.

Idem.

Ibid.p. 60.

9 FOLLONI, André Parmo. Reflexões sobre complexity Science no direito tributário. In: MACEI, Demetrius Nichele et al. (Coord.). Direito tributário e filosofia. Curitiba: Instituto Memória, 2014, p. 24-37. p. 24. 
impedia o exame das partes como um todo, levando ao isolamento de disciplinas e a autonomia das ciências.

Consequentemente, o fenômeno chegou ao direito, o qual foi segregado em disciplinas e, desta forma, em ciências, como a penal, a civil, a tributária ${ }^{10}$. O papel do cientista, nesse contexto, seria o estudo do direito positivo existente, limitando-se à “[...] descrição neutra e imparcial"11.

Apesar de reconhecerem a importância desse método para um determinado espaço e tempo, os cientistas de Santa Fé acreditavam que um novo approach poderia ser extremamente profícuo para o avanço da ciência como um todo e, especialmente, para a econômica. Nesse contexto, W. Brian Arthur ${ }^{12}$ comenta que se o critério definidor da ciência no início do século XX era pautado pelo poder de previsão, pela nítida distinção entre sujeito e objeto, no seu final, essa ideia não mais se sustenta.

Rompe-se com a elegância e precisão matemática de um mundo estático e sem fricções para verificar, no mundo real, o que, de fato, ocorre. Diz-se isso porque uma das principais críticas aos economistas era de que seus modelos teóricos eram simplistas e fugiam da realidade.

Logo, o encontro realizado em 1987, do qual participaram o ganhador do Prêmio Nobel, Kenneth Arrow, além de vários físicos, biólogos, economistas e cientistas da computação, apontou para um caminho, de que a solução dos fenômenos exigem uma visão holística e interdisciplinar, direcionando o pensamento científico à complexidade, abrindo caminho para Complexity Economics.

Tecidas essas considerações iniciais, a proposta a ser desenvolvida no presente artigo é examinar, inicialmente, o surgimento da nova economia institucional e o ferramental fornecido por esta teoria econômica que assenta suas bases na análise das instituições e na influência que exercem nas esferas social, política e econômica da vida humana. Em seguida, será apresentada a Economia da Complexidade (ou Complexity Economics), a fim de se evidenciar a necessidade de uma visão holística da realidade para tornar os mecanismos de resolução de problemas fornecidos pela NEI mais eficientes. Ao final, demonstrar-se-á que o

10 FOLLONI, André; DIB, Natália Brasil; LIMA, Sérgio Fernando Ferreira de. A teoria dos sistemas-mundo de Immanuel Wallerstein: a pesquisa jurídica e o caso do direito tributário. Quaestio Iuris (Impresso), v. 8, p. 2556-2572, 2015. p. 2557.

11 FOLLONI, André; BONAT, Alan Luiz. Incentivos fiscais e suas condições de validade: igualdade e proporcionalidade. Cadernos do Programa de Pós-Graduação em Direito da UFRGS, v. 10, p. 341-362, 2015. p. 344.

12 ARTHUR, W. Brian. The end of certainty in economics. Disponível em <http://tuvalu.santafe.edu/ wbarthur/Papers/End_of_Certainty_Web.pdf >.p. 1 
approach da complexidade não é somente compatível com o instrumental da nova economia institucional, mas também indispensável para o movimento.

\section{A NOVA ECONOMIA INSTITUCIONAL (NEI)}

A análise econômica do direito (AED) promove a interação entre as ciências jurídica e econômica, com a finalidade de expandir a compreensão e o alcance do direito, especialmente no que se refere às consequências de uma opção legislativa ${ }^{13}$. Consequentemente, aplica o ferramental econômico ao arcabouço jurídico, valendo-se dos postulados da escassez, do custo de oportunidade, da escolha racional e maximizadora, bem como a premissa de que pessoas respondem a incentivos ${ }^{14}$.

O movimento possui diferentes abordagens: na AED comportamental, as atenções são voltadas a escolha dos agentes, assumindo a existência de desvios comportamentais; na AED sociológica, estuda-se a possibilidade das normas sociais interferirem na estrutura de incentivos; na AED neo-intstitucionalista "os custos de transação e as instituições passam a ser fundamentais nos modelos empregados"15.

Para o presente artigo, abordar-se-á a nova economia institucional (NEI), que pode ser definida como uma iniciativa interdisciplinar que combina economia, direito, teoria das organizações, ciência política, sociologia e antropologia para compreender as instituições da vida social, política e comercial. Emprega conceitos de várias disciplinas das ciências sociais, mas sua linguagem primária é a econômica. ${ }^{16}$

O principal objetivo do movimento é o de explicar o que são as instituições, como surgiram, quais os propósitos a que servem, e como se alteram através do transcurso de tempo e se e como deveriam ser reformadas. ${ }^{17}$ Vale dizer, a análise econômica realizada pela NEI trata as instituições como o ferramental indispensável para o desenvolvimento, na medida em que instituições fortes e sedimentadas proporcionam um ambiente favorável à realização das trocas. $^{18}$

13 GICO JUNIOR, Ivo Teixeira. Metodologia e Epistemologia da Análise Econômica do Direito. Economic Analysis of Law Review, v. 1, n. 1, p. 7-32, jan./jun. 2010. p. 8.

14 Ibid. p. 22.

15 Ibid. p. 26.

16 KLEIN, Peter G. New Institutional Economics. Encyclopedia of Law and Economics, Universiteit Utrecht, 1999, p. 456. Disponível em: <http://users.ugent.be/ gdegeest/tablebib.htm>. Acesso em: 20 set. 2016.

17 Idem.

18 ROCHA, Lara Bonemer Azevedo da. O desenvolvimento econômico pelo acesso à justiça. 1. ed. Birigui, SP: Boreal, 2015, p. 106. 
Peter Klein afirma que até recentemente a economia institucional usualmente se referia aos estudos de Thorstein Veblen, John R. Commons, Wesley C. Mitchell, Clarence Ayres e seus seguidos. Trata-se de um grupo diverso, mas seu trabalho reflete a respeito de uma série temas comuns, em sua maioria formulando críticas a respeito a economia ortodoxa. Estes autores focavam no coletivo ao invés do individual, tinham uma preferência pelo evolutivo, em detrimento de mecanismos de aproximação da economia e enfatizavam a observação empírica ao invés do raciocínio dedutivo. ${ }^{19}$

Em que pese estas contribuições, os antigos institucionalistas são pouco conhecidos dos economistas contemporâneos. ${ }^{20}$ Neste sentido, a rejeição de Ronald Coase é típica quando afirma que sem uma teoria eles não tinham nada para passar adiante, exceto um material descritivo à espera de uma teoria. ${ }^{21}$

O termo "nova" economia institucional foi originado a partir dos estudos de Oliver Williamson no ano de 1975 com seu estudo sobre os custos de transação, influenciado pelas publicações de Ronald Coase em 1937 sobre a análise da firma, de Hayek em 1937 e 1945 sobre as limitações ao conhecimento dos fatos econômicos, e ainda, de Simon (1947), Arrow (1963), Davis e Douglass North (1971), Alchian e Demsetz (1972) e outros. ${ }^{22}$ A NEI é fortemente representada por Coase, com o estudo sobre o custo social e por North, com o notável trabalho sobre instituições.

Assim como os primeiros institucionalistas a NEI é interessada pelas instituições sociais, econômicas e políticas que orientam a vida humana. Todavia, evita o holismo da escola antiga, na medida em que segue o individualismo metodológico estrito, sempre calçando suas explicações em termos de objetivos, planos e ações dos indivíduos. Diferenciase da escola neoclássica ao insistir que as análises políticas sejam guiadas pelo que Ronald Coase denomina de análise comparativa das instituições ${ }^{23}$, em que as comparações são feitas no âmbito do mercado. Para Coase, a análise de um sistema hipotético pode prover técnicas de análise que não seriam passíveis de aplicação no plano real. É preciso pensar arranjos alternativos que funcionariam na prática. ${ }^{24}$

19 KLEIN, Peter G. New Institutional Economics. Encyclopedia of Law and Economics, Universiteit Utrecht, 1999, p. 456-457. Disponível em: <http://users.ugent.be/ gdegeest/tablebib.htm>. Acesso em: 20 set. 2016.

20 KLEIN, Peter G. New Institutional Economics. Encyclopedia of Law and Economics, Universiteit Utrecht, 1999, p. 457. Disponível em: <http://users.ugent.be/ gdegeest/tablebib.htm>. Acesso em: 20 set. 2016.

21 COASE, Ronald H. The New Institutional Economics. Journal of Institutional and Theoretical Economics, 140, 1984, pp. 229-232, p. 230.

22 KLEIN, Peter G. New Institucional Economics, p. 457.

23 COASE, Ronald H. The Regulated Industries: Discussion, 54 American Economic Review, 1964, 194-197, p. 195.

24 KLEIN, Peter G. New Institucional Economics, p. 458. 
Para organizar os vários ramos da NEI, Davis e $\mathrm{North}^{25}$ apresentam uma distinção entre ambiente institucional e arranjos institucionais.

O ambiente institucional estrutura a ação humana, na medida em que as instituições reduzem as incertezas fornecendo o suporte para o dia-a-dia. No jargão dos economistas, North afirma que as instituições definem e limitam o conjunto de escolhas individuais, na medida em que incluem tanto o que os indivíduos estão proibidos de fazer como também o que é permitido em determinadas condições. ${ }^{26}$

Trata-se de um arcabouço perfeitamente análogo às regras do jogo em um esporte competitivo. ${ }^{27}$ Contudo, ao contrário destas, as diretrizes institucionais surgem espontaneamente, mais como subprodutos das escolhas individuais do que como produtos de escolhas deliberadas em ações coletivas. ${ }^{28}$

Este conjunto de regras que regem o ambiente institucional podem ser formais, traduzidas em regras explícitas como por exemplo, a Constituição, as leis e os direitos de propriedade, e informais, consideradas regras implícitas, como por exemplo as convenções sociais. ${ }^{29}$

As instituições informais são verificas nas tradições, costumes, valores morais, crenças religiosas e outras normas de comportamento que passam pelo "teste do tempo". Conforme pontua Svetovar Pejovich são denominadas "the old ethos", "the hand of the past" e ainda "the carriers of history". São incorporadas à comunidade provocando percepções sobre o mundo, com base no passado e em um rol de valores ${ }^{30}$. Decorrem de informações transmitidas socialmente e que são parte de uma herança, chamada de cultura. A cultura, por seu turno, representa a transmissão de uma geração para a outra, através de ensinamentos e imitações, de conhecimento, valores e outros fatores que influenciam o comportamento

25 DAVIS, Lance E.; NORTH, Douglass C. Institutional Change and American Economic Growth, Cambridge, Cambridge University Press, 1971.

26 NORTH, Douglass C. Institutions, Institutional Change and Economic Performance. New York: Cambridge University Press, 1990. p. 03.

27 Ibid. p. 03-04.

28 HAYEK, F.A. Law, Legislation, and Liberty, vol. 1, Rules and Order, Chicago, University of Chicago Press, 1973.

29 NORTH, Douglass C. Institutions, Institutional Change and Economic Performance. New York: Cambridge University Press, 1990. p. 34.

30 PEJOVICH, Svetovar. The Effects of the Interation of Formal and Informal Institutions on Social Stability and Economic Development. Journal of Markets \& Morality, n. 2 p. 164-181, fall 1999. p. 166. 
humano $^{31}$. Pelo fato de serem herdadas é que Lekovic afirma que não são propensas a mudanças, ou seja, mudam lentamente com o transcurso do tempo, de geração em geração ${ }^{32}$.

As instituições informais, segundo North, desempenharam um papel de relevante importância no decorrer da história, para o desenvolvimento das sociedades mercantis na Europa e para a criação das instituições formais. Afirma que restrições informais podem ensejar em um acordo de menores custos e formas de medição (pesos padronizados e medidas, por exemplo) e fazer a segunda e terceira execução por parte da facção eficaz por meio de dispositivos de sanção ou redes de informação que familiarizavam terceiros com o desempenho de câmbio específico (classificações de crédito, melhores agências de negócios, etc.). Estas organizações e instrumentos que fazem normas de comportamento cooperativo (restrições informais) são eficazes não só em uma grande parte da história de troca mais complexa ao longo da história, mas são notavelmente paralelas com o jogo dos modelos teóricos que produzem resultados de cooperação por meio de recursos que alteram as taxas de desconto e produziam um aumento de informação. O crescimento de formas mais complexas de intercâmbio na Europa ainda medieval e moderna foi possível graças a uma variedade de instituições informais, tais como a antiga lei do comerciante e os códigos de conduta do comerciante publicados ${ }^{33}$.

O modo com que a mente humana processa a informação não é apenas a base para a existência das instituições, como também é a chave para que se que entenda a importância do modo com que as instituições informais influenciam no processo de escolha humana em curto e em longo prazo. Em curto prazo, a cultura da sociedade define o modo com que os indivíduos processam e utilizam a informação e por isso afetam o modo com que as instituições informais são especificadas. E em longo prazo, produzem implicações no processo cultural de informação que constituem a base das instituições informais, desempenhando um importante papel no desenvolvimento das instituições formais ${ }^{34}$.

A lenta transformação das sociedades primitivas, cujas regras de convivência eram baseadas nas tradições e costumes (instituições informais), para as sociedades consideradas complexas, que passaram a ser regidas também pela lei escrita (instituição formal), evidencia

31 NORTH, Douglass C. op. cit. p. 37.

32 LEKOVIC, Vlastimir. Interaction of formal and informal institutions - Impact on Economic Success. Facta Universitatis, Series Economics and Organization, v. 8, n. 4, p. 357-370, 2011. p. 365.

33 NORTH, Douglass C. Institutions, Institutional Change and Economic Performance. New York: Cambridge University Press, 1990, p. 41.

34 Ibid. p. 42; 44. 
o que North denomina de uma "formalização das restrições" (the formalization of constraints $)^{35}$.

Para Eros Grau, "o que transforma uma norma social em norma jurídica é o fato de a massa das consciências individuais chegar à compreensão de que a sanção material desta norma pode ser socialmente organizada", ou seja, "que a reação social contra sua violação pode ser socialmente organizada pelo emprego da coerção". É, segundo Eros Grau, no momento em que a massa dos espíritos concebe a possibilidade de organização social de uma regra, que passa a desejá-la, provocando sua constituição, que enseja no aparecimento da regra de direito ${ }^{36}$.

A elaboração de um sistema formal de regras para lidar com disputas mais complexas implicou a criação de regras formais para definir as relações entre os agentes, ensejando o desenvolvimento das hierarquias, a partir das organizações ${ }^{37}$. As regras formais, segundo North, podem complementar e incrementar a efetividade das restrições informais, na medida em que podem reduzir o custo de informação, de monitoramento e de execução e por isso tornar as instituições informais soluções possíveis para trocas mais complexas, podendo, inclusive, atuar na modificação, revisão ou substituição das instituições informais ${ }^{38}$.

Estas regras formais se materializam por regras políticas, econômicas e pelos contratos. As regras políticas definem de forma geral a estrutura hierárquica da política, sua estrutura decisional básica e as características explícitas da sua agenda de controle. As regras econômicas, por seu turno, definem os direitos de propriedade, e os contratos contém provisões específicas a respeito de um acordo específico em uma troca ${ }^{39}$.

A importância das instituições formais é evidente, na medida em que perfaz o instrumental material que regula os direitos e deveres dos indivíduos em uma sociedade. Contudo, como bem adverte North, muito embora as regras formais estabeleçam a fonte básica do direito material, com o objetivo de testar a performance econômica sob várias condições, o grau com quem estas regras se identificam com a performance é limitado ${ }^{40}$.

Os arranjos institucionais, por sua vez, são guias específicos que Williamson denomina estruturas de governança, estabelecidas entre as partes em uma transação para

35 Ibid. p. 46.

36 GRAU, Eros Roberto. Direito Posto e Direito Pressuposto. 8. ed. São Paulo: Malheiros Editores, 2011. p. 73.

37 NORTH, Douglass C. Institutions, Institutional Change and Economic Performance. New York: Cambridge University Press, 1990, p. 46.

38 Ibid. p. 47.

39 Ibid. p. 47.

40 Ibid. p. 53. 
regular as negociações. Empresas, contratos de longo-termo, burocracia pública, organizações não lucrativas e outros acordos contratuais são exemplos de arranjos institucionais. ${ }^{41}$

O presente estudo é voltado à análise do ambiente institucional para que se possa demonstrar como é positiva e necessária a influência da Teoria dos Sistemas Complexos, para a aplicação correta do ferramental fornecido pela NEI.

Peter Klein afirma que estudos recentes tem dado enfoque ao relacionamento entre o ambiente institucional e processos cognitivos para a formação de um arcabouço para a tomada de decisões em um ambiente permeado por incertezas. ${ }^{42}$ Neste contexto, Denzau e North destacam que a ideologia, juntamente com as instituições, auxiliam os agentes a lidar com decisões complexas. ${ }^{43}$

Longe de ser unânime, haja vista a existência de várias críticas, como por exemplo de Dworkin ${ }^{44}$, Nabais ${ }^{45}$ e, em âmbito nacional, de Misabel de Abreu Machado Derzi, Thomas da Rosa de Bustamante ${ }^{46}$ e José Antonio Savaris ${ }^{47}$, o movimento tem ganhado espaço em âmbito doutrinário e jurisprudencial ${ }^{48}$.

Tecidas estas considerações, revela-se importante saber se a Análise Econômica do Direito brasileira, se encontra amparada isoladamente na teoria da Nova Economia Institucional ou rumou para o caminho da complexidade. Estabelecida essa premissa será possível examinar a pertinência de suas críticas e verificar sua aptidão para atingir o fím a que se destina.

\section{A ECONOMIA DA COMPLEXIDADE}

41 DAVIS, Lance E.; NORTH, Douglass C. (1971), Institutional Change and American Economic Growth.

42 KLEIN, Peter G. New Institutional Economics. Encyclopedia of Law and Economics, Universiteit Utrecht, 1999, p. 530. Disponível em: <http://users.ugent.be/ gdegeest/tablebib.htm>. Acesso em: 20 set. 2016.

43 DENZAU, Arthur; NORTH, Douglass C. Shared Mental Models: Ideologies and Institutions, 47, Kyklos, 1994, pp. 3-31, p. 4.

44 DWORKIN, Ronald. Uma questão de princípio. Tradução Luís Carlos Borges. São Paulo: Martins Fontes, 2000.

45 Na nota de rodapé 26, da página 197, em que visualiza o movimento como a "[...] concepção do direito à maneira de uma empresa cujo objetivo é realizar a afectação economicamente mais eficiente dos recursos escassos do sistema jurídico [...] que faz apelo claramente ao estado mínimo e ao endeusamento dos property rights, ou seja, ao estado liberal". NABAIS, José Casalta. O dever fundamental de pagar impostos: contributo para a compreensão constitucional do estado fiscal contemporâneo. Coimbra: Almedina, 2004. p. 197.

46 DERZI, Misabel de Abreu Machado; BUSTAAMANTE, Thomas da Rosa de. A análise econômica de Posner e a ideia de estado de direito em Luhmann: breves considerações críticas. Rev. Fac. Direito UFMG, Número especial em memória do Prof. Washington Peluso, p. 327-352, 2013.

47 SAVARIS, José Antonio. Uma teoria da decisão judicial da Previdência Social: contributo para superação da prática utilitarista; orientador Marcus Orione Gonçalves Correia - São Paulo, 2010. p. 86-96.

48 DERZI, Misabel de Abreu Machado; BUSTAMANTE, Thomas da Rosa de. A análise econômica de Posner e a ideia de estado de direito em Luhmann: breves considerações críticas. Rev. Fac. Direito UFMG, Número especial em memória do Prof. Washington Peluso, p. 327-352, 2013. p. 327. 
Para compreensão dos sistemas complexos, importante ter em mente a assertiva de José Souto Maior Borges de que o cientista "há sempre que contar com a eventualidade do erro na pesquisa científica"49, haja vista a incapacidade da ciência de garantir o "conteúdo-deverdade" de uma corrente teórica. Como exemplo, o autor pernambucano cita o caso do ocorrido com a física no início do século XX, fundada pela certeza newtoniana e que restou assolapada pela relativista de Einstein, cujos fundamentos expuseram os erros e possibilitaram o progresso tecnológico do qual fazemos uso até hoje $\mathrm{e}^{50}$.

Esse caráter transitório também é delineado por Morin, que comenta sobre o impacto das "inter-retroações" nos desenvolvimentos científico, técnicos e sociológicos, expondo que as ciências transformam a sociedade, mas há um movimento recíproco: a sociedade também transforma a ciência ${ }^{51}$.

Tratam-se, portanto, de relação indissociável: “[...] a ciência está no âmago da sociedade e, embora bastante distinta dessa sociedade, é inseparável dela, isso significa que todas as ciências, incluindo as físicas e biológicas, são sociais" ${ }^{\prime 2}$.

O conhecimento científico busca, ao cabo e ao rabo, apresentar respostas aos problemas da sociedade. Ocorre que, curiosamente, o seu progresso não culmina na extrema segurança quanto ao futuro. Pelo contrário, coloca numa incerteza que nos liberta "de um sonho lendário", sendo considerada, portanto, por Morin, como uma incerteza boa ${ }^{53}$.

Tal premissa se assenta pelo fato de o conhecimento científico não ser formado apenas por "verdades verdadeiras" 54 , é um campo aberto, em que são conflitadas teorias, princípios, visões de mundo e postulados.

Isso não significa, também, que o futuro revela-se totalmente aleatório, imprevisível, mas sim que devem ser consideradas variáveis que uma visão estática e reducionista descartaria.

A pretensão do conhecimento foi objeto do discurso de Friedrich August Von Hayek na ocasião do recebimento do prêmio Nobel de economia em 1974. O professor austríaco, conhecido por sua visão liberal da economia, foi um dos idealizadores da complexidade.

49 BORGES, José Souto Maior. Ciência feliz: sobre o mundo jurídico e outros mundos. Recife: Fundação de Cultura Cidade do Recife, 1994. p. 19.

50 Idem.

51 MORIN, Edgar. Ciência com consciência. Tradução de Maria D. Alexandre e Maria Alice Sampaio. Rio de Janeiro: Bertrand Brasil, 2005. p. 19-20.

52 Ibid. p. 20.

53 Ibid. p. 24.

54 Idem. 
Na década de 70 do século passado, Hayek já criticava a ausência de interação entre ciências, colocando esse como um dos fatores pela criação de um sistema econômico bagunçado, incapaz de gerir a realidade. Isso porque a economia simplesmente desprezava procedimentos exitosos de outras ciências, como a física, por exemplo ${ }^{55}$.

$\mathrm{Na}$ ciência física, ensina Hayek, todo fator que pudesse impactar na determinação de eventos era devidamente considerado, examinado e observado pelos pesquisadores.

Já no tocante à ciência econômica, apenas era reputado como importante aquilo passível de mensuração. Exemplo dessa assertiva é a constatação de Ivo Gico Teixeira Junior de que “[...] os praticantes de AED elaboram modelos teóricos dos problemas que desejam investigar, nos quais apenas as variáveis consideradas relevantes são consideradas" ${ }^{\text {}}$.

Consequentemente, a economia encontrava enorme dificuldade de compreender mercados, notadamente um fenômeno complexo, formado por ações dos mais variados indivíduos e que afetam diretamente o resultado, haja vista a impossibilidade de conhecer a ação de cada um e, assim, de antever resultados. A complexidade ganha espaço nesse cenário, acreditando que a incapacidade de mensurar a ação de cada indivíduo, não implica no descarte desse fator.

Outro exemplo citado por Hayek é o de uma partida de futebol, cujo resultado, por mais que o cidadão detenha dados particulares relevantes sobre os times, é muito difícil de acetar. Se, além do conhecimento geral, o indivíduo tivesse condições de aferir o estado emocional do jogadores, o grau de atenção, a capacidade de física, cardíaca, pulmonar, o nível de stress, o entrosamento, a cada momento haveria uma maior possibilidade de antever o placar $^{57}$.

Contudo, toda essa informação fica fora do alcance científico ou seria demasiado custosa obtê-la, fazendo com que muitos pesquisadores simplesmente a ignorassem. De outro giro, assumir a complexidade de um fenômeno não implica na assertiva de que ele é totalmente imprevisível, fortuito ou aleatório. Há uma certa dose de particularidades nas jogadas, que as tornam previsíveis. Além disso, existem características gerais que se repetem.

Com esse pensamento, um grupo de pesquisadores cansado com as frustrações das previsões econômicas, se reuniu no deserto do Novo México formando o Santa Fe Institute. O

55 HAYEK, Friedrich August Von. Prize Lecture: The Pretence of Knowledge. Nobelprize.org. Nobel Media AB 2014. Disponível em: <http://www.nobelprize.org/nobel_prizes/economicsciences/laureates/1974/hayek-lecture.html>. Acesso em 15 set. 2016.

56 GICO JUNIOR, Ivo Teixeira. Metodologia e Epistemologia da Análise Econômica do Direito. Economic Analysis of Law Review, v. 1, n. 1, p. 7-32, jan./jun. 2010. p. 25.

57 HAYEK, Friedrich August Von. Op. cit. Idem. 
ponto em comum das ideias desses cientistas era de que problemas complexos não podem ser solucionados pela divisão do todo em partes, além do fato de exigirem diferentes perspectivas disciplinares, ou seja, de aportes de biólogos, físicos, químicos, matemáticos ${ }^{58}$.

Outra característica identificada pelos pesquisadores do Santa $\mathrm{Fe}$ Institute foi a enorme dificuldade dos economistas em usar padrões históricos, como recessões econômicas, para fazer estimativas fidedignas, compatíveis com a realidade.

Uma das razões, aduz Beinhocker, foi o distanciamento da micro e macroeconomia. O professor da Universidade de Oxford ensina que a economia pode ser dividida em duas metades: a microeconomia e a macroeconomia. A primeira pode ser definida como a visão de baixo para cima (bottom-up), suas atenções são voltadas para os tomadores de decisão (indivíduos) para, então, chegar aos mercados. Já a macroeconomia parte da perspectiva de cima para baixo (top-down), partindo de uma premissa mais geral, como por exemplo questiona o porque da existência do desemprego, para descer à esfera micro e encontrar uma resposta ${ }^{59}$.

Em que pese possuírem pontos de partida distintos, é inconteste entre os economistas, que tais ramos não podem ser separados ${ }^{60}$. Além disso, a ciência econômica deve proporcionar ao pesquisador mecanismos de iniciar com uma visão micro e chegar à macro e vice-versa. Ocorre que as duas metades, a despeito de compartilharem diversas ideias, técnicas e estruturas, se distanciaram ao longo dos anos, seguindo caminhos diferentes. Para ilustrar esse raciocínio, Beinhocker faz a analogia com o projeto para construção de malha férrea nacional, com o objetivo de atravessar o país inteiro, fosse iniciado por dois grupos, cada um saindo de uma extremidade, com o objetivo de se encontrarem no meio do caminho. Ocorre que a micro e macroeconomia, trabalharam anos e falharam em atingir esse objetivo $^{61}$. Vejamos a razão com um exemplo prático.

As oscilações no ciclo de negócio são um desafio para a microeconomia tradicional. Pelo sistema neoclássico de equilíbrio, o modelo econômico não apresenta oscilações, não se movimenta senão por meio de fatores exógenos, ou seja, seria um mero mecanismo de propagação, que responde a estímulos. Pela economia tradicional, havia a crença no equilíbrio, pois o método partia de dois pilares metodológicos: comportamento racional dos agentes e, como resultado dessa premissa inicial, o equilíbrio. Tal modo de orientação do

58 BEINHOCKER, Eric D. The origin of wealth: evolution, complexity and the radical remaking of economics. Harvard Business School Press: Boston, Massachusetts, 2006. p. 45-46.

59 Ibid. p. 163.

60 Idem.

61 Idem. 
raciocínio, em tempos de crises econômicas, simplesmente relega as causas à fatores externos, sendo incapaz de encontrar as causas ${ }^{62}$.

Do outro lado, onde estão trabalhando os macroeconomistas, há um approach distinto. Por começarem com dados para, daí tentar chegar a uma explicação, tiveram que se afastar do modelo ortodoxo e, consequentemente, da visão micro. Ato contínuo, esse ramo incorporou uma visão imperfeita da racionalidade, bem como passou a visualizar o fenômeno econômico como dinâmico. Como consequência dessa visão, Akerlof chegou ao conceito de informação assimétrica e como isso afeta mercados, tendo sido laureado com o premio Nobel de economia em $2001^{63}$.

E aqui, advém a economia da complexidade ou Complexity Economics, cujo pressuposto é desenvolver uma teoria de agentes, de redes de comunicação e de evolução capaz de melhor compreender o fenômeno social ${ }^{64}$.

A Complexity Economics visualiza os padrões macroeconômicos como fenômenos emergentes (emergent phenomena), dotados de características que emergem de forma endógena, as quais são resultado de interações entre agentes e destes com o ambiente ${ }^{65}$.

Assim, diferentemente do modelo tradicional, a Complexity Economics, acredita que os ciclos de negócios, crescimento e inflação são fenômenos que surgem de forma endógena, ou seja, são resultado de interações ocorridas no próprio ambiente. Por conta disso, a Complexity Economics funda-se nas oscilações, no equilíbrio pontual e na leis de potência ${ }^{66}$.

O movimento de um pêndulo, as vibrações de uma nota musical de uma guitarra e os batimentos cardíacos são exemplos de sistemas oscilatórios. E essa teoria parte do pressuposto que as economias também oscilam, apresentando características similares a de ecossistemas biológicos ${ }^{67}$.

O equilíbrio pontual, igualmente, está relacionado ao processo biológico. Beinhocker comenta que estudiosos, por diversos anos, acreditavam que a evolução seguia um padrão regular de formação de espécies e extinção, seguindo a linha darwiniana. Contudo, em 1972, Eldredge e Goulf, visualizaram fosseis que não seguiam essa regularidade, expondo a importância da interação dos agentes com o ambiente ${ }^{68}$.

62 Ibid. p. 163-164.

63 Ibid. p. 165-166.

64 Ibid. p. 167.

65 Idem.

66 Ibid. p. 168.

67 Idem.

68 Ibid. p. 172-173. 
Por fim, as leis de potência assumem a existência de volatilidade, bem como de informações, tais como notícias, novas tecnologias, que alteram o preços dos produtos e afetam diretamente o sistema econômico. ${ }^{69}$

O pensamento complexo começou a influenciar a escola do Direito e Economia no final do século XX e início do século XXI, quando Denzau e North reconheceram a influência da ideologia dos indivíduos na tomada de decisões. Os autores definem ideologia como um conjunto compartilhado de modelos mentais possuídos por grupos de indivíduos. Estes modelos mentais são as representações internas que sistemas individuais de cognição criam para interpretar o ambiente, ao passo que as instituições são os mecanismos externos à mente criado pelos indivíduos para estruturar e organizar o ambiente. Juntos, ideologia e instituições formam as bases para a atividade econômica sob condições de incerteza. ${ }^{70}$

Também em matéria de contratos a complexidade começou a ganhar espaço. Estudos neste sentido desenvolvidos por Eric Eggleston, Eric A. Posner e Richard Zechauser passaram a sugerir que a complexidade da realidade torna os contratos dificilmente completos. É, pois, impossível atingir a almejada completude contratual quando, principalmente em contratos de longo prazo, não se tem condições de antever todos os fenômenos futuros e as possíveis contingências. $^{71}$

A dinâmica decorrente da interação humana evidencia a forte necessidade de que seja considerada a complexidade dos fenômenos. Do contrário, a eficácia do instrumental de análise da realidade pode ficar à uma considerável distância de estar apta a resolver os problemas a que se propõe a nova economia institucional.

Em resumo, a Complexity Economics, por meio dos mecanismos brevemente expostos nesse item, não se apresenta como a resposta para todos os questionamentos e problemas existentes em mercados, bolsas, ciclos de negócios ou depressões. Contudo, fornece novas ferramentas para demonstrar a existência de vários fatores que interagem e resultam em comportamentos no dia a dia.

69 Ibid. p. 175-181.

70 DENZAU, Arthur; NORTH, Douglass C. Shared Mental Models: Ideologies and Institutions, 47, Kyklos, 1994, pp. 3-31, p. 4.

71 EGGLESTON, Karen; POSNER, Eric. A.; ZECKHAUSER, Richard. Simplicity and Complexity in Contracts. John M. Olin Program in Law and Economics. Working Paper n. 93, Chicago, 2000, p. 01. 


\section{CONSIDERAÇÕES FINAIS}

A Análise Econômica do Direito, principalmente em sua abordagem institucional, evidencia o considerável aprimoramento de seus institutos, com a passagem da Economia Institucional para a Nova Economia Institucional.

Demonstra, outrossim, que a partir da década de 1990 alguns autores norteamericanos passaram a considerar a influência da Economia da Complexidade nos estudos a respeito das instituições. Ainda que não diretamente, verifica-se que a teoria dos contratos incompletos decorre fortemente da consideração de que a realidade em que os contratos são levados a efeito é complexa.

Contudo, no Brasil a utilização da Economia da Complexidade é bastante incipiente. Poucos estudos tem se dedicado a este aspecto, o que conforme exposto neste trabalho, pode comprometer sobremaneira a eficiência que se visa almejar na resolução dos problemas apresentados pela realidade atual.

Assim, verifica-se a necessidade de que os estudos que se utilizam do ferramental do Direito e Economia, principalmente em sua abordagem institucional adotem o caminho da complexidade.

Esta forma de proceder não somente terá o condão de garantir maior realidade ao instrumental da Análise Econômica do Direito, como também afastar as críticas formuladas à esta corrente de pensamento que se fundam, em sua maioria, da perspectiva reducionista da escola.

Sem a pretensão de esgotar o tema, buscou-se demonstrar que a realidade é muito mais complexa do que um mundo em equilíbrio idealizado pelas teorias econômicas das escolas clássicas.

\section{REFERÊNCIAS BIBLIOGRÁFICAS}

ARTHUR, W. Brian. The end of certainty in economics. Disponível em http://tuvalu.santafe.edu/ wbarthur/Papers/End_of_Certainty_Web.pdf.

BEINHOCKER, Eric D. The origin of wealth: evolution, complexity and the radical remaking of economics. Harvard Business School Press: Boston, Massachusetts, 2006.

BORGES, José Souto Maior. Ciência feliz: sobre o mundo jurídico e outros mundos. Recife: Fundação de Cultura Cidade do Recife, 1994. 
COASE, Ronald H. The New Institutional Economics. Journal of Institutional and Theoretical Economics, 140, 1984, pp. 229-232.

COASE, Ronald H. The Regulated Industries: Discussion, 54 American Economic Review, 1964, pp. 194-197.

DAVIS, Lance E.; NORTH, Douglass C. Institutional Change and American Economic Growth, Cambridge, Cambridge University Press, 1971.

DENZAU, Arthur; NORTH, Douglass C. Shared Mental Models: Ideologies and Institutions, 47, Kyklos, 1994, pp. 3-31.

DERZI, Misabel de Abreu Machado; BUSTAMANTE, Thomas da Rosa de. A análise econômica de Posner e a ideia de estado de direito em Luhmann: breves considerações críticas. Rev. Fac. Direito UFMG, Número especial em memória do Prof. Washington Peluso, p. 327-352, 2013.

DWORKIN, Ronald. Uma questão de princípio. Tradução Luís Carlos Borges. São Paulo: Martins Fontes, 2000.

EGGLESTON, Karen; POSNER, Eric. A.; ZECKHAUSER, Richard. Simplicity and Complexity in Contracts. John M. Olin Program in Law and Economics. Working Paper n. 93, Chicago, 2000.

FOLLONI, André Parmo. Reflexões sobre complexity Science no direito tributário. In: MACEI, Demetrius Nichele et al. (Coord.). Direito tributário e filosofia. Curitiba: Instituto Memória, 2014, p. 24-37.

FOLLONI, André; DIB, Natália Brasil; LIMA, Sérgio Fernando Ferreira de. A teoria dos sistemas-mundo de Immanuel Wallerstein: a pesquisa jurídica e o caso do direito tributário. Quaestio Iuris (Impresso), v. 8, p. 2556-2572, 2015.

FOLLONI, André; BONAT, Alan Luiz. Incentivos fiscais e suas condições de validade: igualdade e proporcionalidade. Cadernos do Programa de Pós-Graduação em Direito da UFRGS, v. 10, p. 341-362, 2015.

GICO JR, Ivo. Metodologia e epistemologia da análise econômica do direito. Economic Analysis of Law Review, v. 1, n. 1, p. 7-33, jan./jun. 2010.

GRAU, Eros Roberto. Direito Posto e Direito Pressuposto. 8. ed. São Paulo: Malheiros Editores, 2011.

HAYEK, Friedrich August Von. Law, Legislation, and Liberty, vol. 1, Rules and Order, Chicago, University of Chicago Press, 1973.

HAYEK, Friedrich August Von. Prize Lecture: The Pretence of Knowledge. Nobelprize.org. Nobel Media AB 2014. Disponível em: http://www.nobelprize.org/nobel_prizes/economicsciences/laureates/1974/hayek-lecture.html. Acesso em 15 set. 2016. 
KLEIN, Peter G. New Institutional Economics. Encyclopedia of Law and Economics, Universiteit Utrecht, 1999. Disponível em: http://users.ugent.be/ gdegeest/tablebib.htm. Acesso em: 20 set. 2016.

LEKOVIC, Vlastimir. Interaction of formal and informal institutions - Impact on Economic Success. Facta Universitatis, Series Economics and Organization, v. 8, n. 4, p. 357-370, 2011.

MORIN, Edgar. Ciência com consciência. Tradução de Maria D. Alexandre e Maria Alice Sampaio. Rio de Janeiro: Bertrand Brasil, 2005.

NABAIS, José Casalta. O dever fundamental de pagar impostos: contributo para a compreensão constitucional do estado fiscal contemporâneo. Coimbra: Almedina, 2004.

NORTH, Douglass C. Institutions, Institutional Change and Economic Performance. New York: Cambridge University Press, 1990.

PEJOVICH, Svetovar. The Effects of the Interation of Formal and Informal Institutions on Social Stability and Economic Development. Journal of Markets \& Morality, n. 2 p. 164-181, fall 1999.

ROCHA, Lara Bonemer Azevedo da. O desenvolvimento econômico pelo acesso à justiça. 1 . ed. Birigui, SP: Boreal, 2015.

SAVARIS, José Antonio. Uma teoria da decisão judicial da Previdência Social: contributo para superação da prática utilitarista; orientador Marcus Orione Gonçalves Correia - São Paulo, 2010. 